\title{
Pesquisar para compreender e transformar a nossa própria prática
}

\section{Researching in order to understand and transform our own practice}

\author{
João Pedro da Ponte*
}

\begin{abstract}
RESUMO
No ensino fundamental e médio, tal como no ensino superior, cada vez mais existem professores que empreendem pesquisas sobre a sua própria prática profissional. Fazem-no porque sentem necessidade de compreender melhor a natureza dos problemas com que se defrontam, para poder transformar a sua prática e as suas condições de trabalho. Este artigo começa por apresentar resumidamente as principais características dessa actividade como género de pesquisa. De seguida, descreve a experiência de um grupo de professores e formadores ligados à disciplina de Matemática, em diversos níveis de ensino, que tem empreendido colectivamente uma actividade de aprofundamento e divulgação das suas pesquisas sobre a sua própria prática profissional. E, finalmente, o artigo analisa o que esse trabalho representou para os diversos participantes envolvidos.

Palavras-chave: investigar a prática; desenvolvimento profissional do professor; colaboração.
\end{abstract}

\begin{abstract}
In elementary and secondary schools, as well as at university level, an increasing number of teachers are investigating their own professional practices. They undertake that because they feel the need of better understanding the nature of the problems that they face, in order to

* Professor da Faculdade de Ciências da Universidade de Lisboa. Grupo de investigação DIF - Didática e Formação - Departamento de Educação e Centro de Investigação em Educação.
\end{abstract} E-mail: jp@fc.ul.pt 
transform their practice and working conditions. This paper begins by briefly presenting the main characteristics of this activity as a research genre. Then, it describes the experience of a group of mathematics teachers and teacher educators, from several school levels, who are collectively carrying out an activity of reflecting about their investigations about their practices and presenting then to the professional community. And, finally, the article analyses what that work represented for the participants involved in this work.

Key-words: investigate the practice; professional development; colaboration.

Na sua prática, os profissionais da educação defrontam-se com numerosos problemas, muitos dos quais de grande complexidade. Entres esses, contam-se o insucesso de seus alunos, relativamente a objectivos de aprendizagem curricular e até a objectivos básicos de socialização e enculturação; a desadequação dos currículos e programas em relação às necessidades e condições dos públicos a que se destinam; o modo ineficaz e desgastante como funcionam as instituições educativas; a incompreensão de grande parte da sociedade, a começar pelos meios de comunicação social, para as condições extremamente adversas em que se trabalha na educação.

Em vez de esperar por soluções vindas do exterior, muitos profissionais têm vindo cada vez mais a pesquisar directamente os problemas que se lhes colocam ${ }^{1}$.

Isso acontece igualmente em campos como a saúde, o trabalho social e o desenvolvimento rural.

São várias as razões pelas quais esta pesquisa pode ser importante. Ela contribui, antes de mais, para o esclarecimento e resolução dos problemas. Além disso, proporciona o desenvolvimento profissional dos respectivos actores e ajuda a melhorar as organizações em que eles se inserem. Em certos casos, esta pesquisa pode ainda contribuir para o desenvolvimento da cultura profissional no respectivo campo de prática e até para o conhecimento da sociedade em geral (PONTE, 2002).

Não se trata de transformar os professores em pesquisadores profissionais. Trata-se de reforçar a competência profissional do professor, habilitando-o a usar a pesquisa como uma forma, entre outras, de lidar com os problemas com que se defronta:

${ }^{1} \mathrm{O}$ carácter crescente deste movimento é notado, por exemplo, por HITCHCOCK e HUGHES (1989) e, mais recentemente, por ZEICHNER e NOFFKE (2001). 
Educar pela pesquisa tem como condição essencial primeira que o profissional da educação seja pesquisador, ou seja, maneje a pesquisa como princípio científico e educativo e a tenha como atitude cotidiana. Não é o caso fazer dele um pesquisador "profissional", sobretudo na educação básica, já que não a cultiva em si, mas como instrumento principal do processo educativo. Não se busca um "profissional da pesquisa", mas um profissional da educação pela pesquisa. (DEMO, 2000, p. 2)

A pesquisa dos profissionais sobre a sua prática é muitas vezes feita em colaboração com outros profissionais e com outros actores sociais. Tratandose de uma actividade complexa, que se debruça sobre um objecto também ele complexo, há toda a vantagem em recorrer aos esforços conjuntos de uma equipa de trabalho. A colaboração é uma estratégia fundamental para lidar com problemas ou dificuldades que não resolver a um nível puramente individual, como os que a cada momento surgem na actividade profissional. $\mathrm{Na}$ verdade, hoje em dia, a colaboração constitui um elemento importante de muitos projectos envolvendo professores e educadores universitários (ANDRÉ, 2001; CHRISTIANSEN et al., 1997; COCHRAN-SMITH \& LYTLE, 1999).

É usual distinguir-se entre cooperação e colaboração (KRAINER, 2003; MOREIRA, 2001). A cooperação envolve diversas pessoas a trabalhar em conjunto para o mesmo fim. As relações entre os participantes podem ser bastante desiguais e os seus objectivos individuais podem ser bastante distintos. Em contrapartida, na colaboração, os diversos participantes trabalham em conjunto com relativa igualdade e numa relação de ajuda mútua, procurando atingir objectivos comuns. Ela pressupõe negociação cuidadosa, tomada colectiva de decisões, comunicação, diálogo e aprendizagem por parte de todos os intervenientes (DAY, 1999; ERICKSON, 1989).

Para além dos objectivos comuns entre os diversos participantes que existem num trabalho de colaboração, cada um deles tem, naturalmente, os seus próprios objectivos individuais, decorrentes da sua função profissional, da sua personalidade e dos seus projectos. Isso reforça o seu envolvimento no trabalho e o seu sentido de realização pessoal. Assim, num trabalho de colaboração, a existência de objectivos comuns fortes não é incompatível com o prosseguimento de objectivos individuais próprios por cada um dos intervenientes. Conseguir a articulação entre esses dois tipos de objectivos não é fácil, mas é uma condição fundamental para o êxito do trabalho.

Uma actividade de colaboração pressupõe um certo nível de organização e exige, igualmente, um certo tipo de ambiente relacional. A organização não tem de ser totalmente definida logo no início. Na verdade, é mais comum 
que ela assuma formas diferentes conforme as etapas do trabalho, tornandose mais intensa à medida que o processo avança e os intervenientes se conhecem melhor e ganham confiança uns nos outros. $\mathrm{O}$ ambiente relacional pressupõe uma relação de confiança entre os participantes. Para que isso aconteça, é necessário diálogo que estabeleça uma comunicação efectiva, conduzindo a uma compreensão dos significados e problemas com que cada um se defronta. A criação deste ambiente requer uma constante negociação de significados, de objectivos e de processos, permitindo o estabelecimento de pontos comuns que viabilizem o trabalho conjunto. E, finalmente, envolve cuidado, levando os intervenientes a prestar uma genuína atenção aos problemas e necessidades dos parceiros. Desse modo, a colaboração pressupõe um certo nível de mutualidade na relação entre os participantes, em que todos recebem e todos dão algo uns aos outros.

Num grupo que se propõe realizar uma actividade complexa, em condições frequentemente adversas, a liderança é fundamental (COCHRAN-SMITH \& LYTLE, 1999). Tal liderança pode ser centrada numa pessoa, ser partilhada por um grupo ou ser relativamente distribuída por todos. Um ou outro estilo pode ser mais adequado aos propósitos do grupo e às características dos seus membros. Além disso, num trabalho de colaboração, é natural que exista uma diferenciação de papéis entre os membros da equipa. Essa divisão permite uma melhor realização das diversas tarefas, possibilitando alcançar com maior qualidade e mais rapidamente o objectivo visado. No entanto, tal divisão pode ter um lado negativo, atribuindo a alguns dos participantes os papéis mais interessantes e a outros o trabalho de rotina, gerando desigualdade de estatutos dentro da equipa. Para além disso, o trabalho de colaboração envolve dificuldades em relação às quais é necessário estar atento, como o saber gerir a diferença, lidar com a imprevisibilidade, saber avaliar os potenciais custos e benefícios e evitar a auto-satisfação confortável e o conformismo (BOAVIDA e PONTE, 2002).

A pesquisa dos profissionais da educação sobre a sua prática filia-se em diversas tradições intelectuais, profissionais e académicas. Uma delas é o movimento em torno do professor pesquisador (STENHOUSE, 1975). No entanto, esse termo tem o inconveniente de centrar as atenções no professor individual e não no professor integrado numa equipa colaborativa. Além disso, muitas vezes os professores fazem pesquisas sobre questões que pouco têm a ver com a sua prática. Por exemplo, analisando cerca de uma centena de teses de mestrado realizadas por professores de Matemática em Portugal nos anos 80 e 90, SERRAZINA e OLIVEIRA (2001), referem que apenas seis delas constituem pesquisas sobre problemas da sua própria prática. 
Outro conceito muito próximo do de pesquisa sobre a prática é o de pesquisa-acção. No entanto, a natureza e objectivos da pesquisa-acção são caracterizados de modo muito diverso por vários autores, dando origem a intermináveis polémicas ${ }^{2}$. Para alguns, há um único modo de se fazer pesquisa-acção, aquele que prossegue certos objectivos, subordinados a uma preocupação de justiça e mudança social, sendo os aspectos especificamente profissionais considerados meramente técnicos e relegados para segundo plano. Não é essa a opção que assumo neste artigo, que não desvaloriza qualquer dos elementos do trabalho do professor, sejam eles práticos ou teóricos, cognitivos ou relacionais, axiológicos, conceptuais ou técnicos ${ }^{3}$. O ponto de partida da indagação do professor pode parecer modesto, mas quando ele inicia um processo de questionamento genuíno no interior da sua uma prática, nunca se sabe aonde irá chegar. Desse modo, a pesquisa do profissional sobre a sua própria prática é orientada por valores, mas não está ao serviço de quaisquer valores - a não ser os valores da qualidade da educação e do questionamento e reflexão.

Uma terceira tradição também próxima é a do profissional reflexivo (schöN, 1983). Na verdade, não se concebe alguém que faça pesquisa sobre a prática e não seja reflexivo. Mas não basta certamente ser reflexivo para se fazer pesquisa (LÜDKE, 2001). Além disso, o conceito de professor reflexivo admite interpretações bastante diversas. Para alguns, todo o ser humano é reflexivo e, por isso, todo o professor é necessariamente reflexivo, enquanto que, para outros, ser reflexivo implica várias condições, por vezes bastante restritivas. Desse modo, a maior ou menor proximidade entre os conceitos de pesquisar e reflectir sobre a prática depende sobretudo do sentido que se dá a esses termos.

Interessa, por isso, clarificar o que significa pesquisar. Na minha perspectiva, trata-se de um processo fundamental de construção do conhecimento que começa com a identificação de um problema relevante - teórico ou prático - para o qual se procura, de forma metódica, uma resposta convincente

${ }^{2}$ Ver, por exemplo, KEMMIs, 1993; MOREIRA, 2001; ZEICHNER e NOFFKE, 2001. Certos autores, como KEMMIS (1993), identificam pesquisa-acção com investigação dos profissionais sobre a sua própria prática. Outros autores, como ZEICHNER e NOFFKE (2001), consideram tratar-se de conceitos distintos, posição que tomo também neste artigo.

${ }^{3}$ Uma posição semelhante parece tomar LÜDKE (2001) quando aponta a necessidade de "abertura para todas as formas de pesquisar que sejam necessárias para a busca de soluções aos seus problemas [do professor], sem comprometer o próprio estatuto de pesquisa" (p. 52). 
que se tenta validar e divulgar. BEILLEROT (2001) sugere três condições para que uma actividade se possa considerar uma pesquisa: (i) produzir conhecimentos novos, (ii) ter uma metodologia rigorosa, e (iii) ser pública. Essas condições têm a sua razão de ser. Na verdade, se uma questão já foi anteriormente respondida, em vez de pesquisa temos verificação ou comprovação. Além disso, uma pesquisa deve seguir algum método com um certo rigor e permitir que todos os interessados possam compreender o que foi feito. Assim, uma pesquisa tem de poder ser apreciada e avaliada pela comunidade interessada que, para isso, precisa de a conhecer. Só assim os resultados e perspectivas emergentes dessa pesquisa podem ser aceites como válidos e relevantes pelo grupo profissional e, possivelmente, pela comunidade educativa em geral ${ }^{4}$. Se isso é verdade para toda a pesquisa, também o será, em particular, para aquela que os profissionais realizam sobre a sua própria prática. A característica definidora dessa forma de pesquisa refere-se apenas ao facto que o pesquisador tem uma relação muito especial com o objecto de estudo ele não estuda um objecto qualquer, mas sim um aspecto da sua própria prática profissional.

As três condições indicadas por BeILlERot são, no entanto, muito gerais. Será preciso operacionalizá-las por meio do desenvolvimento de uma cultura de pesquisa e de discussão da pesquisa sobre a prática profissional. Só com a análise de casos concretos se estabelecerá com clareza o que é realmente novo, o que é metódico e rigoroso e o que foi divulgado publicamente de modo a ser escrutinado e discutido pelos pares. Ou seja, a pesquisa envolve uma metodologia mas envolve também uma pergunta directora e uma actividade de divulgação e partilha. Por isso, a existência de uma metodologia é uma condição necessária mas não suficiente para caracterizar uma actividade como pesquisa e, em particular, uma pesquisa sobre a nossa própria prática.

Tem-se discutido se pesquisar sobre a nossa própria prática profissional poderá constituir, ou não, um novo paradigma de pesquisa educacional (ANDERSON; HERR, 1999; ZEICHNER; NOFFKE, 2001). Tendo em conta a variedade de actores educativos que podem interessar-se por esta actividade, a multiplicidade das suas experiências, objectivos e motivações é bastante duvidoso que isso possa acontecer. No entanto, parece-me razoável que considere que ela constitui um género de pesquisa, com os seus traços próprios e

\footnotetext{
${ }^{4}$ Note-se que esta condição não é considerada essencial por certos autores, como ZEICHNER e NOFFKE (2001).
} 
definidores, sem deixar por isso de assumir numerosas variantes e pontos de contacto com outros géneros e tradições de pesquisa ${ }^{5}$.

\section{A experiência do grupo de estudos do GTI}

O grupo de estudos "O professor como investigador" 6 constitui um interessante exemplo de um trabalho colaborativo de profissionais interessados em estudar a sua própria prática. Vejamos, primeiro, as principais etapas da actividade do grupo em $2000-02^{7}$, para fazermos, depois, uma análise crítica desse trabalho.

\section{A constituição do grupo}

O grupo de estudos surgiu para promover o aprofundamento da interface entre a investigação educacional e o ensino, acabando por se centrar no tema "O professor como pesquisador". O início formal do trabalho é em Abril de 2000, depois de um processo de negociação que durou quase ano e meio sobre os objectivos da actividade a realizar. Compõem o grupo, nesta altura, cerca de dezena e meia de participantes, professores do ensino fundamental, médio e superior, alguns dos quais formadores de professores (formação inicial e continuada). Todos eles tinham realizado ou estavam a realizar trabalhos de mestrado ou doutorado. O grupo propõe-se, então, a recolher e divulgar informação sobre o tema, promovendo o desenvolvimento profissional

${ }^{5}$ Por exemplo, COCHRAN-SMith (1999) refere as seguintes formas de pesquisa pelos professores: pesquisa-acção, estudos autobiográficos, autoestudo (selfstudy), pesquisa reflexiva (reflexive inquiry), tornar-se um estudante do ensino (becoming a student of teaching) e estudo do ensino e aprendizagem (p. 8).

${ }^{6}$ Esse grupo é promovido pelo Grupo de Trabalho de Investigação (GTI) da Associação de Professores da Matemática (APM) de Portugal.

${ }^{7}$ Presentemente, o grupo continua activo, discutindo questões relacionadas com esta temática e trabalhando em novas iniciativas. 
dos seus membros, e define as actividades a realizar - identificar bibliografia, explorar sites, analisar e discutir textos e preparar a edição de uma colectânea.

Inicialmente, realizam-se cerca de duas reuniões por trimestre e a filiação no grupo é relativamente fluida. Ao lado de membros com elevada assiduidade, outros faltam com frequência e alguns, por uma razão ou por outra, deixam de participar. De vez em quando, novos participantes vão ingressando no grupo. As discussões neste período incidem em questões como: Que tipos de problemas podem os professores estar interessados em pesquisar? Que pesquisa pode um professor fazer? Que critérios podem ser usados para tornar credível tal pesquisa? Esta actividade é compatível com as restantes responsabilidades de um professor? Que formação é necessária para a realizar? A pouco e pouco, a ênfase vai-se deslocando do actor (o professor que pesquisa) para o objecto a investigar (os problemas que identifica na sua própria prática). Desse modo, começa a falar-se cada vez menos no "professor como pesquisador" e cada vez mais na "investigação sobre a nossa própria prática".

Na primeira reunião do grupo de estudos, fica estabelecido que uma das actividades a realizar é a edição de uma colectânea. Prevê-se que esta seja constituída por textos escritos originalmente em português ou traduzidos, escolhidos entre aqueles que o grupo iria analisar. No entanto, na reunião de Dezembro de 2000, volta-se a discutir a possível estrutura desta publicação e começa a tomar forma a ideia desta incluir também artigos originais elaborados, quer por membros do grupo, quer por outros professores e pesquisadores portugueses que tivessem desenvolvido trabalho nesta área. Esta ideia vinha-se consolidando nas discussões à medida que se sente que a maioria dos textos de autores de outros países tem pouco a ver com a realidade portuguesa.

\section{De grupo de estudos a grupo de trabalho}

Na reunião de Outubro de 2001 dá-se um novo passo na identificação do conteúdo da publicação visada pelo grupo. Abandona-se, definitivamente, a ideia de produzir uma colectânea com textos já existentes e decide-se produzir um livro constituído, fundamentalmente, por artigos originais. Essa mudança em relação ao possível conteúdo da publicação é decisiva na vida do grupo, levando ao estabelecimento de uma nova dinâmica de trabalho. 
Nessa reunião, definem-se, nas suas linhas gerais, o conteúdo, a estrutura e o método de elaboração do livro. Estabelece-se que será subordinado ao tema "investigação sobre a nossa própria prática" e define-se que os artigos a incluir podem ser de natureza mais teórica, incidindo em aspectos gerais do tema, ou referir-se a experiências realizadas ou em curso em Portugal. Prevêse que todos os membros do grupo estejam envolvidos no processo de elaboração do livro, quer produzindo artigos, quer colaborando no aperfeiçoamento dos artigos produzidos pelos colegas. Estabelece-se a dimensão desejável e a estrutura dos textos, contendo relatos de experiências. Finalmente, combina-se que cada participante deve começar por indicar um título e um resumo relativos à sua contribuição e enviá-lo a todos os membros do grupo antes da reunião seguinte, de modo a que possam ser aí analisados. Toma assim forma o processo de trabalho adoptado daí em diante. E, desse modo, o grupo de estudos transforma-se num grupo de trabalho e, sem perder de vista o desenvolvimento profissional dos seus membros, passa a ter como eixo organizador da sua actividade a publicação do livro numa data acordada por todos.

A partir de Novembro de 2001 inicia-se a produção dos textos, trabalho que assume um ritmo bastante intenso durante o primeiro semestre de 2002. Vários professores de Matemática e formadores de professores são, então, convidados a participar, uma vez que se sabe que tinham realizado, recentemente, pesquisas relacionadas com a sua própria prática profissional.

Num primeiro momento, os resumos de cada contribuição são discutidos pelo grupo. Dessa análise, resultam algumas sugestões para a elaboração da primeira versão de cada artigo. É estabelecido um calendário de trabalho que permite que essas versões iniciais sejam previamente analisadas por cada um dos participantes e, posteriormente, discutidas no grupo. $\mathrm{O}$ objectivo dessas discussões é apresentar sugestões que possibilitem a elaboração de novas versões mais aperfeiçoadas. Essas são novamente enviadas a todos, analisadas e discutidas, e o ciclo repete-se até cada artigo assumir a sua forma definitiva.

Por um lado, esse processo é algo moroso e trabalhoso para todos e, por vezes, um tanto frustrante, na medida em que nem sempre é fácil integrar tudo o que é sugerido ou chegar a um consenso sobre o que é importante alterar em cada texto. No entanto, por outro lado, surgem momentos de discussão muito enriquecedores. Com efeito, com o desenvolvimento do trabalho do grupo nesta segunda fase, vão emergindo novas interrogações mais directamente relacionadas com o tema da pesquisa sobre a sua própria prática e o foco das discussões desloca-se para questões como: Que vantagens e dificuldades pode ter um professor em pesquisar sobre a sua própria prática pro- 
fissional? Que relação há entre pesquisar e reflectir? Qual o possível papel da colaboração? O que nos dizem as experiências em que temos estado envolvidos sobre o alcance deste tipo de trabalho? E sobre as suas dificuldades e constrangimentos?

Nos seus aspectos gerais, foi esse processo que presidiu à elaboração do livro Reflectir e investigar sobre a prática profissional (GTI, 2002), título que só é fixado já perto do final do processo, em Maio de 2002. O objectivo dessa publicação é dar a conhecer aos profissionais da educação matemática a problemática da pesquisa sobre a prática, ilustrando-a com casos concretos de trabalhos de pesquisa realizados em Portugal. A relevância dessa publicação decorre do reconhecimento, cada vez maior, pelos profissionais da educação do valor dessa pesquisa, como meio de promover o desenvolvimento profissional e organizacional e como contributo para a produção de conhecimento relevante nessa área.

O livro contém dez relatos de pesquisas realizadas por professores e formadores de professores, cujo conteúdo analiso adiante com mais detalhe. No seu conjunto, esses artigos revelam que realizar pesquisa sobre a própria prática é uma actividade que desperta grande interesse nos respectivos actores e que pode proporcionar significativas implicações para a sua prática profissional $^{8}$.

\section{Problemas, metodologia e divulgação}

Mais atrás, indiquei como elementos fundamentais caracterizadores da pesquisa, a existência de problemas significativos, relacionados com a prática profissional dos seus autores, uma metodologia sistemática e rigorosa e

${ }^{8}$ Além desses artigos, a publicação inclui ainda três ensaios de natureza teórica, dois dos quais redigidos por equipas de dois elementos. Neles discute-se o alcance da pesquisa sobre a sua prática, confrontando o significado desta perspectiva com o significado de reflexão e de outras actividades como a pesquisa académica e a pesquisa-acção e analisam-se possíveis critérios de qualidade deste género de pesquisa. Dá-se, ainda, atenção ao papel da colaboração e da reflexão na actividade do professor, que procura pesquisar sobre a sua prática. O livro contém, ainda, dois textos produzidos em 2001 e uma bibliografia temática, que ajudam a documentar o trabalho anterior nesse campo, bem como uma pequena nota biográfica sobre os autores, para ajudar a perceber o seu interesse por esse tipo de trabalho. 
formas de divulgação na sua comunidade de referência. Vejamos como se situa o livro Reflectir e investigar em relação a esses pontos.

Os relatos de pesquisa incluídos no livro apresentam uma descrição da respectiva questão orientadora e da metodologia, indicam os resultados ou evidências obtidas e discutem as suas implicações para a prática profissional do respectivo autor. As experiências dizem respeito a trabalho realizado em aulas do ensino fundamental e médio e em programas de formação inicial e contínua de professores. O Quadro 1 indica o nome dos autores, a sua actividade profissional, o nível de escolaridade ou de formação da experiência, os problemas propostos para pesquisa e os aspectos principais da metodologia usada.

Deve notar-se que os problemas que servem de base aos artigos não foram propriamente planeados em conjunto. Quando integraram o grupo, os diversos participantes tinham já experiências e pesquisas em desenvolvimento ou recentemente concluídas e são essas experiências que relatam. Desse modo, o mérito principal do grupo de estudos não está na promoção das pesquisas, mas sim no apoio a uma reflexão mais aprofundada sobre elas e num trabalho concertado de divulgação e partilha com a comunidade profissional. 
PONTE, J. P. da. Pesquisar para compreender e transformar...

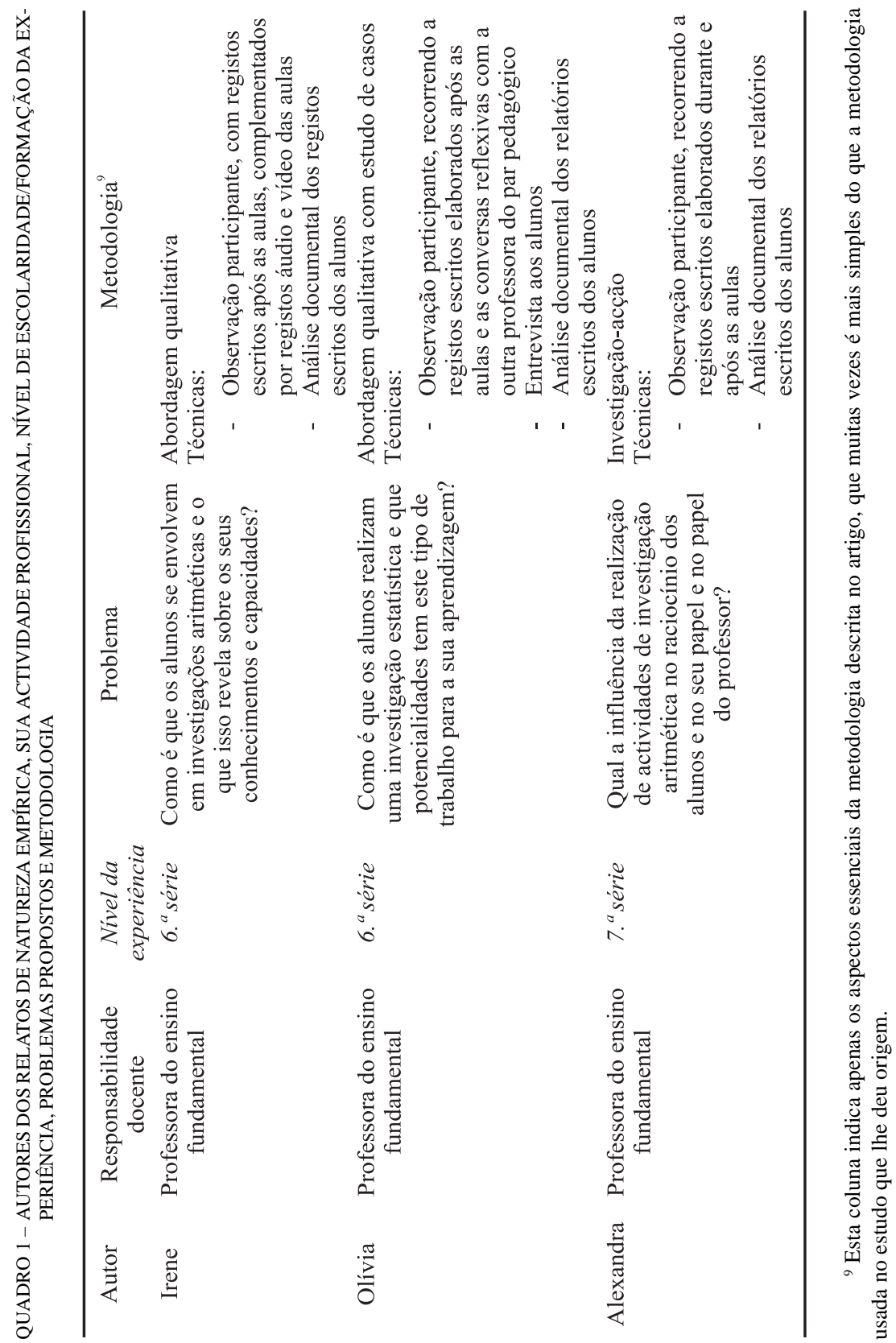




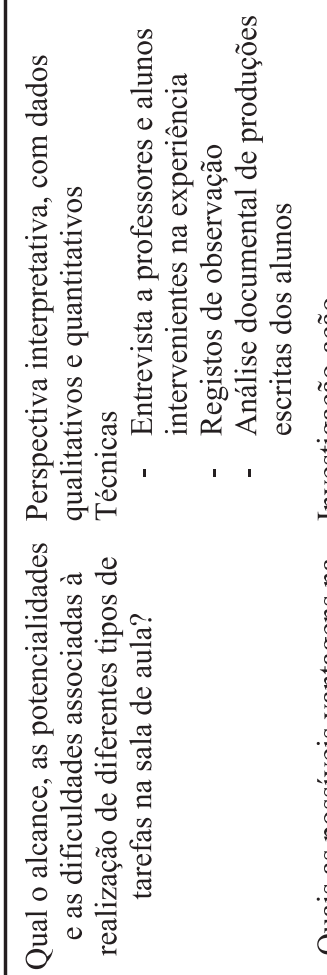

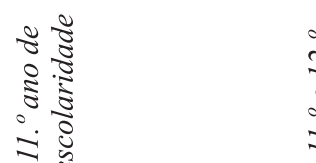

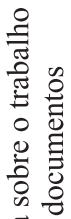

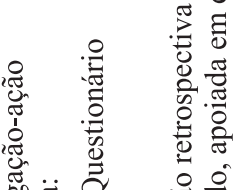

खु

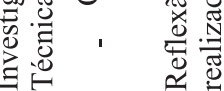

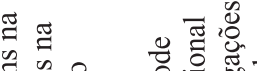

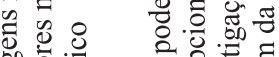

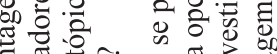

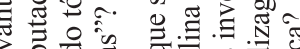

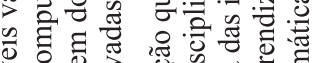

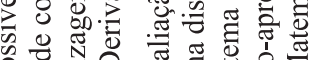

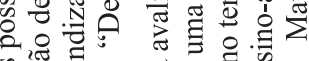

व

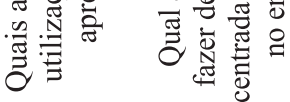

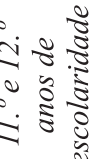

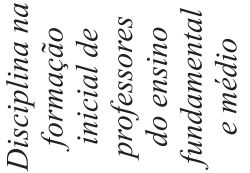

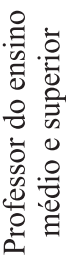

:옳

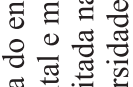

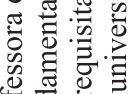

造 胥

$\stackrel{\frac{\pi}{0}}{\stackrel{0}{0}}$

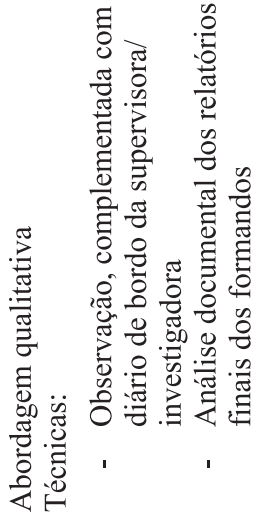

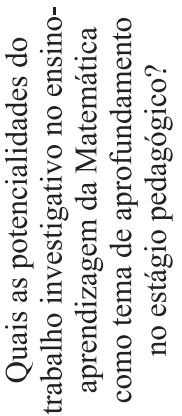

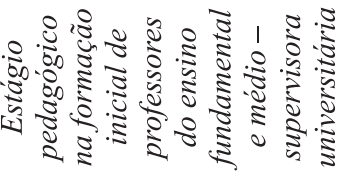

을

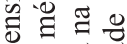

음 $\frac{0}{\pi} \frac{\pi}{\pi} \cdot \frac{\pi}{0}$

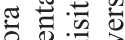

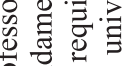

品

$\stackrel{\overparen{7}}{\leftrightarrows}$ 


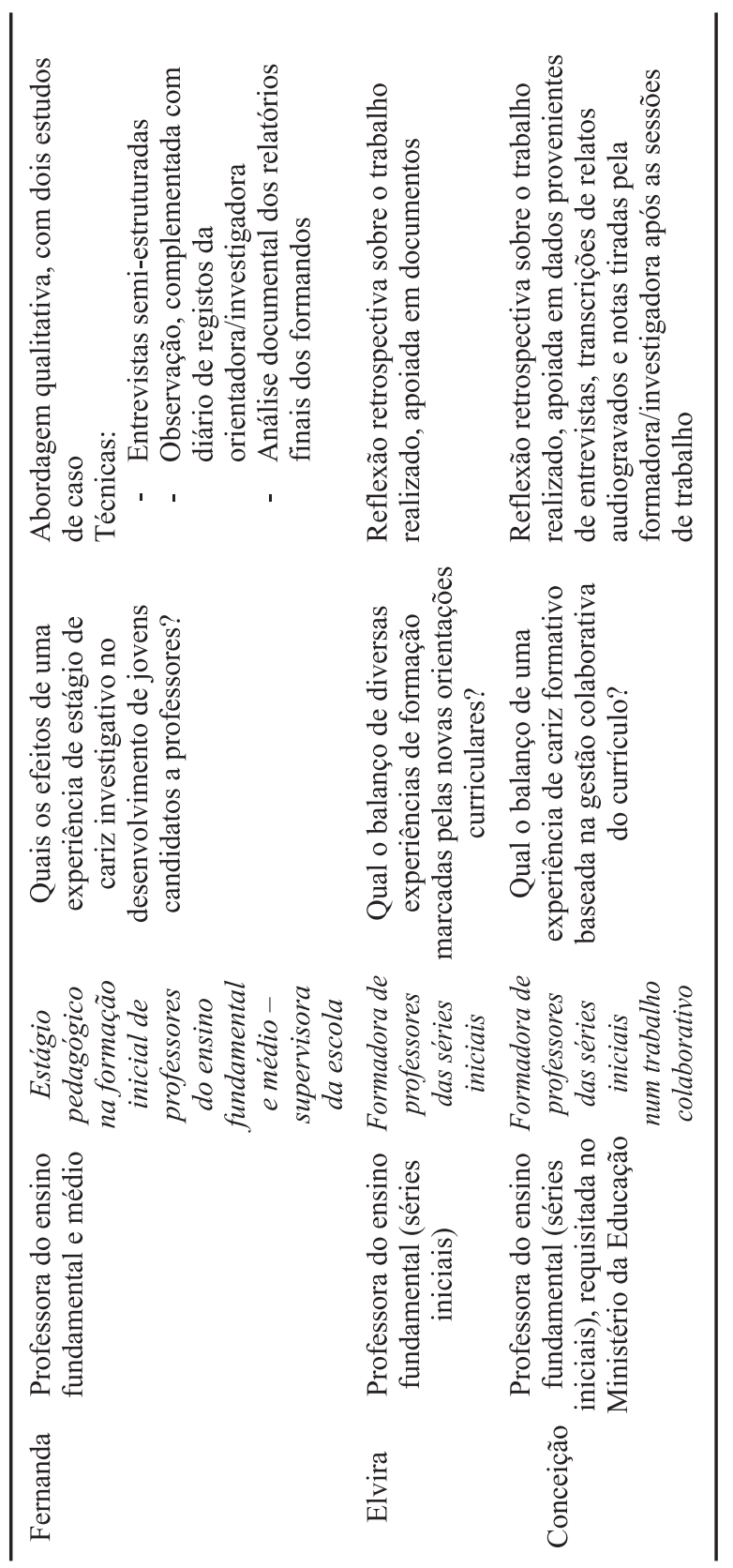


Cinco dos trabalhos dizem respeito à actividade dos autores como professores do ensino fundamental e médio e outros cinco à sua actividade como formadores de professores. No primeiro conjunto, destaca-se claramente o interesse pelo estudo das potencialidades e problemas associados à realização de investigações matemáticas na sala de aula, um tema muito discutido em Portugal (ver, por exemplo, PONTE; BROCARDO; OLIVEIRA, 2003). Três dos artigos debruçam-se directamente sobre essa questão. Outro artigo, procura analisar as potencialidades e dificuldades associadas à realização de um leque alargado de tarefas, em que se incluem a resolução de problemas, a modelação, os exercícios e o trabalho de projecto. Finalmente, o quinto artigo dá especial atenção às tecnologias de informação e comunicação para promover a aprendizagem. Esse conjunto de artigos visa dar informação ao professor sobre modos de trabalho inovadores na sala de aula de Matemática, os seus eventuais efeitos em termos de aprendizagem, bem como elementos a ter em conta pelo professor para que tal trabalho seja bem-sucedido.

No segundo conjunto de trabalhos, reconhece-se um primeiro grupo de três artigos centrado na formação do professor para a realização de investigações matemáticas na sala de aula, na formação inicial - em disciplinas na universidade e no estágio supervisionado. Dois outros artigos referem-se a experiências de formação contínua, marcadas pelas novas orientações curriculares para o ensino da Matemática, em que assumem um papel importante as tarefas a desenvolver, a diversificação de estratégias e materiais (incluindo materiais manipuláveis e tecnologias de informação e comunicação), e a visão do papel do professor e do aluno. Em ambos os casos, a inspiração é sobretudo curricular. Os três primeiros artigos são desenvolvidos a partir de uma ideia curricular específica e os outros dois têm por base uma perspectiva curricular abrangente e integradora. Neste conjunto de artigos, está subjacente um desejo do formador de conhecer o alcance de certas perspectivas curriculares (mais específicas ou mais gerais), e ao mesmo tempo reflectir sobre o seu papel como formador e os modos de trabalho que melhor podem contribuir para alcançar os seus objectivos.

Nas metodologias de pesquisa predomina, claramente, a abordagem qualitativa, em consonância com a tradição prevalecente na educação matemática em Portugal. Três dos artigos apresentam-se essencialmente como reflexões retrospectivas sobre trabalho anteriormente realizado, mas na sua base estiveram igualmente estudos de cunho qualitativo. Apenas um artigo se apresenta de inspiração quantitativa. No seio desta tendência geral "qualitativa" surgem diversas variantes: dois artigos apresentam-se como investigação- 
acção, vários incluem de forma explícita ou implícita estudos de caso e apenas um invoca explicitamente o carácter interpretativo.

Nas técnicas de recolha de dados surgem com bastante evidência a observação participante, a entrevista e a análise documental. A observação participante é frequentemente apoiada num diário de bordo ou de registos, em que o investigador toma as suas notas descritivas e reflexivas sobre os acontecimentos que presenciou na sala de aula ou em sessões de trabalho com professores. Essas observações apoiam-se por vezes em registos áudio e vídeo. As entrevistas assumem predominantemente um cunho semi-estruturado e são realizadas para obter a perspectiva pessoal dos intervenientes sobre as suas próprias experiências. Finalmente, a análise documental incide sobre materiais produzidos pelos intervenientes (desde simples registos efectuados na aula a relatórios bastante elaborados) bem como materiais relativos à instituição e ao contexto escolar. Num caso ou noutro, são também usados questionários, tendo em vista conhecer o ponto de vista de um grupo relativamente numeroso.

Embora os artigos difiram bastante no pormenor com que apresentam as suas opções metodológicas e as suas técnicas de recolha e análise de dados, nota-se, de um modo geral, uma relativa sofisticação metodológica. Isso é explicável, em grande medida, pelo facto de se tratar de trabalhos em curso ou concluídos, realizados na sua maioria no âmbito de cursos de mestrado.

A divulgação na comunidade de referência constitui o ponto central do trabalho promovido pelo grupo de estudos. A escrita desses artigos no seio do grupo, tendo por base trabalhos concluídos ou em desenvolvimento, ajudou os autores a apresentar num grupo restrito o seu trabalho e a sua reflexão, sujeitando-se à crítica e à discussão, em sucessivas etapas de aperfeiçoamento. Por outro lado, a disponibilização do livro à comunidade profissional e académica constitui uma outra faceta de divulgação das pesquisas, a que se juntou a divulgação da experiência colectiva do próprio grupo de estudos. Desse modo, foram múltiplas as instâncias de debate com elementos exteriores relativamente ao trabalho realizado pelo grupo, incluindo as experiências individuais que o compõem. Assim, em termos gerais, parecem satisfeitos os critérios relativo à natureza investigativa do trabalho - existência de um problema relevante, rigor metodológico adequado e carácter público. Resta saber que balanço fazem dessa actividade os seus actores, e é esse ponto que iremos abordar em seguida. 


\section{O balanço crítico da experiência}

As perspectivas teóricas fundamentais elaboradas neste trabalho e alguns exemplos dos relatos de experiências foram apresentados por diversos membros do grupo em encontros nacionais e internacionais e em cursos e seminários em diversas instituições. Esse diálogo com outros membros da comunidade educativa interpelou o grupo para reflectir mais aprofundadamente sobre o percurso realizado. No quadro da tradição de trabalho do grupo, decidiu-se que essa reflexão seria elaborada por escrito a partir de um questionário previamente enviado a todos os membros. As respostas obtidas foram analisadas e devolvidas a todos ${ }^{10}$. É essa análise que apresento a seguir, dando especial atenção à reflexão dos participantes sobre o que aprenderam, as dificuldades experimentadas e os factores mais importantes no seu percurso no grupo.

\section{Aprendizagens e desenvolvimento profissional dos participantes}

Todos os participantes indicam que ao longo deste processo realizaram diversas aprendizagens, aprofundaram capacidades e competências e sentiram desenvolver-se profissionalmente em vários aspectos. Em primeiro lugar surgem, desde logo, aprendizagens referente ao tema "o professor como investigador" e no que respeita à capacidade de reflexão sobre a prática. É o que atestam diversos testemunhos:

[Sinto ter aprofundado] conhecimentos relacionados com o tema do grupo e [ter desenvolvido a minha] capacidade de reflexão [...] por exemplo, perspectivas sobre "professor como investigador", "investigação-aç̧ão", "professor reflexivo", significado, valor e funções da investigação sobre a prática profissional, questões relacionadas com a investigação sobre a própria prática. (Ana)

${ }^{10} \mathrm{Um}$ relato mais pormenorizado dos procedimentos usados nesta reflexão e do balanço realizado pelo grupo é feito em PONTE e SERRAZINA (2003). 
O conhecimento que neste momento possuo sobre o tema é, indubitavelmente, fruto da experiência vivida [no grupo]. Associadas a este novo conhecimento estão, sem dúvida, novas perspectivas relativamente ao que significa investigar sobre a prática e as implicações de uma postura dessa natureza na minha prática profissional. Concretamente, ganhei uma nova consciência do que tem sido, até aqui, o meu desempenho enquanto orientadora, bem como do papel que posso assumir na compreensão e eventual reformulação desse desempenho. (Fernanda)

Esta experiência, ao ter como temática - "O professor como investigador" - contribuiu para que aprofundasse um assunto ainda pouco explorado (pelo menos por mim!) e certas competências que me poderão ajudar a desenvolver investigações futuras. (Helena)

Em termos mais específicos, a investigação sobre a prática profissional tem-me dado o enquadramento para os trabalhos dos meus alunos que fazem a disciplina de Seminário, [professores das séries iniciais em] complementos de formação [...]. Comecei a direccionar os trabalhos dos alunos no sentido da investigação sobre a sua própria prática e isso deu um outro sentido (para mim), ao meu trabalho como tutora nesses seminários. Espero que também aos meus alunos. (Isolina)

Alguns dos participantes (como Ana) assumem fortes interesses no campo da teoria e destacam aspectos conceptuais relacionados com a reflexão e a investigação-acção. Outros (como Fernanda) apontam que essa actividade lhes permitiu um repensar das suas experiências profissionais anteriores. Outros, ainda, relevam aspectos relacionados sobretudo com o desenvolvimento de novas competências ou conhecimentos importantes para as suas funções profissionais presentes (Isolina, Fernanda) ou para a realização de projectos futuros (Helena).

Um segundo aspecto em que diversos participantes se sentiram a crescer profissionalmente diz respeito à capacidade de trabalhar em equipa, ou seja, de trabalhar colaborativamente. Este, aliás, tinha sido um dos aspectos mais discutidos no grupo e constitui o tema de um dos textos teóricos elaborados para a publicação:

Esta experiência para mim trouxe acima de tudo novas aprendizagens. [...] No modo de trabalho, de me expor, de ouvir, de ser capaz de ouvir. Contribuiu, ou melhor, criou em mim novas maneiras de ver as coisas e de perceber melhor o que pode ser um trabalho de grupo. (Elvira) 
[Reforcei a] ideia de que o trabalho colaborativo quando bem conduzido e com metas claras é muito produtivo. (Isolina)

Como referi atrás, trabalhar em colaboração não é fácil. Em particular, torna-se necessário estabelecer uma relação de diálogo franco e aberto com os outros participantes, que implica exposição, vulnerabilidade, abertura às críticas, aspectos eminentemente relacionais (aqui apontados por Elvira). Implica também uma boa organização e liderança (como salienta Isolina). Trata-se de aspectos que, muitas vezes, são dados como adquiridos, mas que também muitas vezes estão longe de estar presentes no modo como nos relacionamos uns com os outros em trabalho de equipa.

Um terceiro campo de competências assinalado por alguns dos participantes diz respeito à comunicação, especialmente no que se refere à redacção de discurso reflexivo de natureza profissional.

[Sinto que desenvolvi] competências de comunicação orais e escritas decorrentes do esforço, quer de explicitar interpretações pessoais relativas a vários textos teóricos lidos e de fundamentar sugestões consideradas relevantes relacionadas com os artigos a incluir na publicação, quer de organizar, de uma forma articulada e coerente, as ideias a incluir no artigo escrito para a publicação. (Ana)

A um outro nível, mas nem por isso menos importante, a experiência de elaboração de um artigo e a oportunidade de apresentar uma conferência trazem consigo o desenvolvimento de competências que de outra forma dificilmente se verificariam [...] (Fernanda)

Saliento [...] aprender como se deve "ler" um artigo; aprender a redigir um artigo. (José)

Na verdade, dada a importância que a escrita assumiu neste processo, não é de admirar que vários participantes sublinhem ter desenvolvido significativamente as suas competências neste campo.

Duas professoras participantes, ambas das séries iniciais $\left(1 .^{\mathrm{a}}-4 .{ }^{\mathrm{a}}\right)$, destacam o desenvolvimento da sua autoconfiança: 
Como novas capacidades, talvez destaque maior confiança em mim própria, mais consciência e segurança na afirmação daquilo que sei e daquilo que não sei e o reforço de uma ideia que já tinha, e é esta "mesmo que seja difícil, eu sou capaz". (Conceição)

Nunca julguei ser capaz de produzir algo que [os outros] tivessem gostado [...] O ter sido capaz talvez me tenha marcado muito mais do que imaginam. (Elvira)

Provavelmente, não será por acaso que esse aspecto é valorizado sobretudo por professoras das séries iniciais, um dos subgrupos profissionais da classe docente em que é mais forte o estigma de menoridade e de falta de capacidade de realização de projectos profissionais.

Finalmente, um sentimento geral de desenvolvimento profissional e de consolidação de uma atitude reflexiva é também apontado por vários participantes como um dos aspectos que consideram mais salientes nessa actividade:

Esta experiência acrescentou algo de novo na minha forma de estar no ensino: perceber que existem mais pessoas preocupadas e interessadas em melhorar o ensino da Matemática, que reflectem sobre a sua prática, possibilitou o renascer da esperança que o ensino pode melhorar e que, se calhar, poderei dar um pequeno contributo nesse sentido. (Alexandra) Contribuiu, tal como as experiências anteriores, para me sentir profissionalmente mais competente. Penso que nesta altura a minha prática profissional é pautada por uma atitude reflexiva mais constante e consciente [...] Numa primeira fase, essa reflexão só existia pontualmente, em situações muito concretas (realização de trabalhos e envolvimento em projectos). Hoje, sinto necessidade de reflectir sobre a minha prática profissional (como professora na sala de aula, como gestora de currículo, como elemento de uma escola...) de um modo fundamentado. Estar inserida numa equipa de professores que desenvolve trabalho colaborativo enriquece a reflexão feita e confere-lhe credibilidade. (Irene)

Uma professora já com bastante experiência (Irene) destaca uma atitude geral reflexiva, algo mais profundo do que o envolvimento pontual em projectos. Pelo seu lado, uma professora ainda com pouco tempo de serviço (Alexandra) parece exprimir sobretudo uma percepção de desenvolvimento da sua identidade profissional, num sentido de participação e intervenção na cultura profissional. 
Em resumo, os participantes indicam que essa actividade contribuiu de modo significativo para um melhor conhecimento do que está envolvido na actividade do professor como investigador da sua prática profissional, sentem ter desenvolvido a sua competência para o trabalho colaborativo, capacidade de comunicação, sobretudo ao nível escrito, e a sua autoconfiança, e experimentaram, em diversos casos, uma sensação de desenvolvimento profissional e de reforço da sua atitude reflexiva.

\section{Reflexão sobre as dificuldades experimentadas}

Se é importante ter noção do que os participantes consideram que se pode aprender na realização desse tipo de trabalho, também será significativo compreender as dificuldades que consideram que ele envolve. Uma primeira ordem de dificuldades, mencionada por vários intervenientes, diz respeito à compatibilização entre o trabalho a realizar no âmbito do grupo com outros compromissos profissionais e pessoais. É uma dificuldade que surge constantemente como "falta de tempo", uma vez que este também é necessário para outras actividades, sendo difícil atender a todas as prioridades:

Os momentos em que senti que não produzi como devia. Quando não tinha tempo para ler os textos todos ou quando não conseguia traduzir adequadamente aquilo que pensava e fazia. (Conceição)

A minha participação no grupo - tal como a dos demais elementos [constituía] uma actividade paralela a acrescer às obrigações profissionais - e outras - que fazem parte do meu dia-a-dia de professora numa escola do ensino básico e secundário. Como tal, por vezes, tornava-se complicado cumprir em tempo útil as tarefas que eram distribuídas no grupo e que pela minha parte assumia. (Fernanda)

A maior dificuldade foi a deslocação, pois tinha de me deslocar do Porto a Lisboa. O tempo disponível, que a partir de uma certa altura se associou [a] falta de saúde, foi outra dificuldade. (José)

Uma segunda ordem de dificuldades, apontada por um número significativo de participantes, diz respeito ao processo de escrita dos respectivos artigos: 
As dificuldades surgiram, sobretudo, durante o processo de escrita. Foi necessário muito tempo para organizar as ideias e encontrar a melhor estrutura e formato para o artigo. (Alexandra)

Outra dificuldade foi a produção de texto. O exercício de passar para o papel as reflexões feitas [levou-me] a tomar consciência de que algumas dessas reflexões não tinham o grau de profundidade necessário, exigindome uma reflexão mais minuciosa de alguns aspectos. Também a necessidade de exprimir com clareza as ideias de forma a poderem ser apropriadas por outros exige alguma prática de escrita, a qual não faço com regularidade. (Irene)

As dificuldades tiveram a ver com a minha natureza dispersa e tarefista. Gosto de reflectir sobre as coisas, mas tenho dificuldade em escrever sobre isso, até porque muitas vezes as ideias não estão assim tão amadurecidas como eu imagino que estão [... Meto-me] em várias coisas em simultâneo, porque essa é a minha maneira de estar, de me sentir bem. Mas, e a profundidade do tratamento dos assuntos? (Manuela)

Os professores, sobretudo os ligados à disciplina de Matemática, na sua maioria, estão pouco habituados a escrever e têm uma relação difícil com a escrita. Uma das professoras (Manuela), associa à sua dificuldade em escrever, aspectos da sua personalidade, que a levam a envolver-se em muitas actividades em simultâneo e, em consequência, a ter pouca possibilidade de reflectir de modo aprofundado sobre tudo o que vai fazendo. Esta má relação com a escrita é uma dificuldade muito específica, mas claramente percebida pelos participantes, o que terá a ver sobretudo com a grande importância que essa actividade assumiu no decurso da presente experiência. Ganhar gosto por se exprimir por escrito será certamente um dos grandes desafios para a afirmação de uma cultura de investigação sobre a sua prática profissional por parte dos professores, em particular os professores dessa disciplina.

Um campo de dificuldades, também referido por diversos professores, diz respeito a alguma insegurança e falta de autoconfiança, nomeadamente para realizar o trabalho colectivo assumido pelo grupo:

As maiores dificuldades foi pensar e acreditar de que era capaz de fazer algo de positivo e contribuir para o trabalho de grupo. (Elvira)

[Tive] preocupação e receio de não conseguir fazer um produto que não envergonhasse o grupo. (Manuela)

Senti alguns momentos de desalento nos períodos de muito trabalho aliados a uma sensação de não ser capaz de dar resposta ao que me era 
pedido. Não era nada agradável o sentimento de culpa que me acompanhava quando não fazia o [trabalho]. No entanto, o gosto pelo trabalho conjunto, a consciência do que perdia se desistisse e a constatação de que os outros também tinham dificuldades mas continuavam, foram mais fortes do que a vontade de desistir. (Olívia)

Ainda no campo afectivo, vários participantes apontaram como dificuldade um sentimento de alguma inibição perante o grupo:

Também, por vezes, o facto de o grupo ter muitos elementos inibia-me um pouco, tornava-se difícil prestar atenção a todos [...] No princípio quando numa primeira reunião estava tudo ainda muito indefinido e as motivações das pessoas eram tão diversas que parecia ser impossível congregar esforços e afectos. Senti-me muito desconfortável [...] Falar à vontade num grupo implica uma relação de confiança que vai sendo construída [...] (Isolina)

A capacidade que reconheço a este grupo provoca em mim alguma inibição. (Elvira)

Finalmente, uma professora (Irene) refere ter tido dificuldade na leitura de textos em inglês. Essa dificuldade respeita, sobretudo, à primeira fase do trabalho, dedicada, sobretudo, à leitura e discussão de textos:

Uma das dificuldades foi a leitura e interpretação de textos escritos em inglês. Contudo essa dificuldade foi de certo modo colmatada pela riqueza das discussões que se produziram no grupo. Houve reuniões para as quais fui com ideias muito pouco claras sobre os textos que iriam ser discutidos, contudo, a análise feita por outros elementos do grupo permitiram-me, na maior parte das vezes, integrar-me nas abordagens feitas. (Irene)

Em resumo, os professores apontam dificuldades e constrangimentos de ordem bastante diversa. Em primeiro lugar, surge a compatibilização do trabalho a realizar no âmbito do grupo com outros compromissos, depois vêm 
aspectos de natureza afectiva e relacional, como a insegurança e a falta de autoconfiança e alguma inibição perante o grupo, e, finalmente, aparecem dificuldades no campo da comunicação associadas ao processo de escrita e também, num caso, de leitura de textos em língua inglesa.

\section{Reflexão dos participantes sobre os factores importantes no seu percurso}

Identificados diversos campos de desenvolvimento e aprendizagem profissional e reconhecidas as principais dificuldades apontadas pelos participantes, importa agora perceber o que eles nos dizem sobre os factores que contribuíram para o seu percurso ao longo deste trabalho.

De um modo muito forte, praticamente todos os participantes se referem ao ambiente colaborativo que se construiu e à dinâmica assumida pelo grupo como elementos decisivos nessa experiência. A generalidade dos membros do grupo põe a tónica no espírito de partilha, no ambiente informal e nas relações interpessoais, sublinhando, alguns deles, a diversidade de experiências e expectativas dos intervenientes:

Essa experiência proporcionou-me a vivência de momentos muito ricos pela partilha, pela troca, pela reflexão, pela crítica e pela autocrítica, pelo trabalho, pelo esforço, pela perseverança, pela camaradagem, pelos conhecimentos adquiridos... (Conceição)

$\mathrm{O}$ ambiente informal, nas reuniões, proporcionado pelos elementos do grupo, possibilitou uma maior descontracção dos presentes, resultando numa maior interacção [...] A sinceridade dos elementos do grupo nos momentos em que efectuavam as críticas aos artigos. (Alexandra)

O grupo foi formado por pessoas (que o incorporaram de livre vontade) com experiências profissionais diversas e provavelmente expectativas bastante diferentes em relação ao trabalho que se iria desenvolver, o que poderia ter constituído uma dificuldade para o seu bom funcionamento. Contudo essa diversidade foi liderada de forma a potencializar os contributos de cada um, tendo contribuído para criar um ambiente de trabalho agradável, onde se desenvolveram e fortaleceram relações interpessoais. (Irene)

O principal factor que terá contribuído para esse desenvolvimento foi, no meu entender, o trabalho colaborativo desenvolvido, que permitiu a 
partilha de saberes e experiências diversificadas, dentro do grupo [...] Destaco o ambiente nas reuniões e as relações interpessoais. (Olívia)

Na perspectiva dos participantes, os aspectos afectivos e relacionais tiveram um papel fundamental no êxito do trabalho, o que, de resto, vai de encontro ao que diz muita da literatura sobre colaboração profissional.

Ao lado desses aspectos, são vários os participantes que apontam a metodologia seguida, centrada na elaboração, discussão e aperfeiçoamento dos textos sobre experiências profissionais e o ritmo de trabalho seguidos como importantes nesse processo:

O processo de trabalho... Gosto de ler e ter com quem discutir o que leio e, nesse sentido, esse grupo foi excelente [...] Também nesse grupo havia colegas que tinham ideias com que me identifico e, às vezes, isso é muito importante... Saber que o que se defende tem eco noutros, em educação (como provavelmente noutras áreas) esse aspecto assume grande relevância. O fluir da discussão e o ritmo das sessões sem pressão, mas sentindo que se estava a fazer alguma coisa e que, numa dada altura, ia ser possível ver o fruto desse trabalho foi também muito positivo. $\mathrm{O}$ eclodir de ideias, o processo de criar foi também aqui visível e isso faz sempre passar energia... [...] Tudo isso resultou porque o grupo era suficientemente aberto, embora com uma coordenação que tinha um papel organizador, e porque as descrições eram feitas (já na fase da escrita dos artigos) após um período de leituras e de discussões em grupo. Penso que essa primeira fase foi importante para a construção não só das ideias mas também de relações empáticas fundamentais no trabalho colaborativo. (Isolina)

Aquilo que retenho de mais positivo foi, sem dúvida, os processos de trabalho, em particular, o apoio que os elementos mais conhecedores e experientes deram aos outros e a forma construtiva como se processaram as revisões das diferentes versões que iam sendo elaboradas. (Fernanda) Penso que foi uma das experiências mais relevantes em termos do meu percurso profissional. Terão contribuído para isso o ritmo das actividades que me forçou a superar o meu próprio ritmo, a organização dos processos de trabalho que nos responsabilizou a todos pelo trabalho final e a pertinência dos objectivos [...] As recordações mais positivas, de satisfação e confiança, referem-se mais à fase final das actividades - a escrita dos textos. Terão contribuído para esses sentimentos, as críticas construtivas feitas por alguns elementos do grupo. Essas críticas aos vários textos, feitas por quem já tinha experiência de escrita de textos, 
tornou possível melhorar a minha própria escrita e constituiu um factor decisivo no desenvolvimento das minhas capacidades críticas. (Olívia) Essa experiência foi muito especial. Tenho participado em muitos projectos e também dinamizado alguns. Os grupos vivem da iniciativa dos seus participantes, mas também da forma como se coordenam. Aqui vivi quer a experiência da iniciativa dos participantes em escrever, ler e criticar os textos, que foi mais conseguida por alguns, quer a percepção da existência de uma coordenação mais ou menos formalizada, que sempre assegurou que os prazos se cumprissem, que as reflexões se fizessem e que fisicamente os materiais saíssem. (Manuela)

Um grupo relativamente numeroso requer uma atenção especial aos processos de trabalho e precisa de uma liderança atenta e discreta para conseguir atingir os seus objectivos, aspecto aqui salientado por diversos participantes (Fernanda, Isolina, Manuela).

Uma das características mais marcantes da metodologia do grupo foi a ênfase na escrita. Isso trouxe dificuldades substanciais, como já referimos, a vários dos participantes. Mas são também vários os que reconhecem ter sido um aspecto determinante para os resultados alcançados:

A questão mais destacada, do ponto de vista profissional, foi o cimentar da certeza, que é muito importante escrever sobre as reflexões que se fazem, não só porque isso nos ajuda a pensar sobre elas e sobre a sua relevância (o que já referi) mas porque é alguma coisa de mais sólido que fica, que se divulga, que põe outros a pensar. É menos efémero do que as experiências confinadas ao indivíduo ou ao local de trabalho. É importante em termos sociais. Essa aprendizagem derivou directamente da metodologia adoptada pelo grupo: escrever, escrever, escrever, e da insistência na preferência de isso ser feito de forma a poder ser efectivamente lido. (Manuela)

A discussão dos textos em conjunto permitiu-me fazer uma leitura desses textos bastante mais rica do que a que teria feito numa reflexão individual. A escrita e discussão dos textos que produzimos constituiu também uma mais valia, impossível de ser conseguida individualmente, quer no que diz respeito à estrutura do texto, quer quanto ao seu conteúdo. A partilha de saberes e experiências foi muito rica, pelo menos para mim. (Olívia) Reflectir sobre um tema que me interessava com outros parceiros era por si só já bastante aliciante. Contudo, o trabalho realizado superou as minhas expectativas. Não estava prevista a produção de textos, o que na minha perspectiva veio, por um lado, dar forma ao trabalho de análise e 
reflexão desenvolvido durante várias sessões de trabalho e por outro lado, permitir a divulgação do estudo feito. (Irene)

Duas participantes sublinham, muito em especial, as características especiais desse grupo, pela diversidade das pessoas que o compunham e pela natureza da actividade que realizava, em que os objectivos e o percurso iam sendo construídos, passo a passo, de modo colectivo:

Foi fundamental no meu percurso. Andava há muito à procura e não sabia bem como... Nem onde... Nem com quem... Porque preciso de "olhar para dentro" mas fazê-lo só é muito penoso. Além disso, nem sempre vemos o que é necessário ver, então, um olhar crítico mas amigo, é indispensável. (Conceição)

Noutros grupos em que participei, por exemplo, em projectos, senti-me desde o início a fazer parte de uma equipa que tinha objectivos muito claros... Quando as pessoas começaram a marcar reuniões/sessões sabiam para que era, o que se esperava que acontecesse, mesmo que fosse para alguns não fazerem nada... Ora isso aqui não era claro de início, foi-se construindo a própria ideia do que fazer e mesmo a segurança de alguns para intervir e mais tarde escrever... Vai-se sempre construindo (ou desconstruindo) em qualquer situação mas, neste caso, penso que essa construção foi emergindo e, em diferentes momentos, para cada um de nós. (Isolina)

Como diz Conceição, uma das professoras participantes, tratou-se de "um processo concebido, construído, partilhado, reflectido... pelo grupo", uma actividade "que foi crescendo e transformando-se".

Em resumo, para o sucesso desse trabalho, na perspectiva dos participantes, contribuíram de modo decisivo o ambiente colaborativo, as relações interpessoais, a dinâmica e a metodologia usada, assente, numa primeira fase, na leitura e discussão de textos e, na segunda fase, na elaboração, discussão e aperfeiçoamento de textos sobre as suas experiências profissionais. Para a criação desse ambiente e dessa dinâmica foram determinantes o tipo de liderança, largamente partilhada pelo grupo, e o carácter emergente dos seus objectivos e processos de trabalho. 


\section{Conclusão}

O facto de a experiência desse grupo ter sido positiva e gratificante para os que nela participaram não nos deve fazer esquecer que a pesquisa dos profissionais sobre a sua própria prática se depara usualmente com muitos problemas e dificuldades - desde as condições sociais e institucionais adversas, à falta de tempo e, frequentemente, de autoconfiança e de formação dos seus protagonistas.

A pesquisa dos profissionais sobre a sua própria prática pode ter significados bem diversos, conforme os propósitos dos actores envolvidos. Para os professores do ensino fundamental e médio, ela pode ajudar a resolver problemas prementes ou contribuir para uma melhor compreensão do que se passa na sua prática. Para os docentes do ensino superior, ela pode significar um campo de trabalho de onde não só resultam elementos importantes para a sua actividade profissional, como ressaltam contributos, em termos de conhecimento, para a respectiva comunidade académica. Se para os primeiros essa pesquisa parece apontar para uma transformação profunda (eventualmente inverossímil) da sua identidade profissional, para segundos, muitos dos quais com treino como pesquisadores e com a pesquisa no seu horizonte profissional, o que está em causa é sobretudo um redireccionamento dos seus interesses e prioridades.

Tanto para os docentes do ensino fundamental e médio como do ensino superior, o desenvolvimento de práticas de pesquisa sobre a sua prática profissional depende do estabelecimento de comunidades profissionais que valorizem, discutam e se apropriem dos resultados desses trabalhos. Os problemas da legitimidade epistemológica desse género de pesquisa, da eticidade dos processos de trabalho e dos critérios de validade a estabelecer (discutidos, por exemplo, por ANDERSON e HERR, 1989; BREEN, 2003; PONTE, 2002; ZEICHNER e NOFFKE, 2001), requerem certamente muito trabalho teórico e reflexão, mas requerem também, e sobretudo, a emergência de comunidades de pesquisa que proporcionem uma base experiencial e social.

Cada grupo profissional está assim perante o desafio de encontrar as formas de conduzir pesquisa sobre a sua própria prática adequadas às suas condições e necessidades. Essa actividade pode emergir de práticas associativas baseadas na troca de experiências, bem como de tradições intelectuais como a pesquisa-acção (KEMMIS, 1993), o professor reflexivo (ALARCÃO, 2001), ou da própria pesquisa académica, como no caso do grupo de estudos do GTI. Os ca- 
minhos são múltiplos e diversas são certamente as formas de que tal pesquisa se pode revestir. Mas para ser capaz de compreender e transformar a realidade, a pesquisa sobre a nossa própria prática profissional não pode descurar a reflexão sobre si mesma e o seu sentido autocrítico, debatendo o seu trabalho na sua comunidade de referência e dialogando também com outros actores sociais apostados na promoção de uma educação de qualidade para todos.

\section{REFERÊNCIAS}

ALARCÃO, I. Professor-investigador: Que sentido? Que formação? In: CAMPOS, B. P. (Ed.). Formação profissional de professores no ensino superior. v. 1. Porto: Porto Editora, 2001. p. 21-31.

ANDERSON, G. L.; HERR, K. The new paradigm wars: Is there room for rigorous practitioner knowledge in schools and universities? Educational Researcher, v. 28, n. 5, p. 12-21, 40, 1999.

ANDRÉ, M. (Ed.). O papel da pesquisa na formação e na prática dos professores. Campinas: Papirus, 2001.

BEILlEROT, J. A Pesquisa: esboço de uma análise. In: ANDRÉ, M. (Ed.). O papel da pesquisa na formação e na prática dos professores. Campinas: Papirus, 2001. p. 71-90.

BOAVIDA, A.; PONTE, J. P. Investigação colaborativa: Potencialidades e problemas. In: GTI (Org.). Reflectir e investigar sobre a prática profissional. Lisboa: APM, 2002.

BREEN, C. Mathematics teachers as researchers: Living on the edge? In: BISHOP, A. J. et al. (Eds.). Second international handbook of mathematics education. Dordrecht: Kluwer, 2003. p. 523-544.

CHRISTIANSEN, H. et al. (Eds.). Recreating relationships: collaboration and educational reform. Albany, NJ: State University of New York Press, 1997.

COCHRAN-SMITH, M.; LYTLE, S. L. Relationship of knowledge and practice: Teacher learning in the communities. Review of Research in Education, n. 24, p. 249305, 1999.

DAY, C. Developing teachers: the challenge of lifelong learning. London: Falmer, 1999.

DEMO, P. Educar pela pesquisa. Campinas: Autores Associados, 2000. 
ERICKSON, F. Research currents: Learning and collaboration in teaching. Language Arts, v. 66, n. 4, p. 430-441, 1989.

GTI (Ed.). Reflectir e investigar sobre a prática profissional. Lisboa: APM, 2002. HITCHCOCK, G.; HUGHES, D. Research and the teacher. London: Routledge, 1989. KEMMIS, S. Action research. In: HAMMERSLEY, M. (Org.). Educational research: current issues. v. 1. London: Paul Chapman, 1993. p. 177-190.

KRAINER, K. T. Communities \& networks. Journal of Mathematics Teacher Education, v. 6, n. 2, p. 93-105, 2003.

LÜDKE, M. A complexa relação entre o professor e a pesquisa. In: ANDRÉ, M. (Ed.). O papel da pesquisa na formação e na prática dos professores. Campinas: Papirus, 2001. p. 27-54.

MOREIRA, M. A. A investigação-acção na formação reflexiva do professor estagiário de inglês. Lisboa: Instituto de Inovação Educacional, 2001.

PONTE, J. P. Investigar a nossa própria prática. In: GTI (Ed.). Reflectir e investigar sobre a prática profissional. Lisboa: APM, 2002. p. 5-28.

; BROCARDO, J.; OLIVEIRA, H. Investigações matemáticas na sala de aula. Belo Horizonte: Autêntica, 2003.

; SERRAZINA, L. Professores e formadores investigam a sua própria prática: o papel da colaboração. Zetetiké, v. 11, n. 20, p. 51-84, 2003.

SCHÖN, D. A. The reflective practioner: how professionals think in action. Aldershot Hants: Avebury, 1983.

STENHOUSE, L. An introduction to curriculum research and development. London: Heineman Educational, 1975.

ZEICHNER, K.; NOFFKE, S. Practitioner research. In: RICHARDSON, V. (Org.). Handbook of research on teaching. $4^{\text {th }}$ ed. Washington, DC: Aera, 2001. p. 298-330.

Texto recebido em 15 mar. 2004 Texto aprovado em 28 ago. 2004 